\title{
A visible-light response vanadium-doped titania nanocatalyst by sol-gel method
}

\author{
Jeffrey C.-S. Wu*, Chih-Hsien Chen \\ Department of Chemical Engineering, National Taiwan University, No. 1, Sec. 4, Roosevelt Rd., Taipei, Taiwan 10617, ROC
}

Received 25 October 2003; received in revised form 17 January 2004; accepted 13 February 2004

\begin{abstract}
A series of vanadium-doped $\mathrm{TiO}_{2}$ catalysts were synthesized by two modified sol-gel methods. V-doped $\mathrm{TiO}_{2}$ was found to be mainly preserved its anatase phase after calcination at $400{ }^{\circ} \mathrm{C}$. The TEM micrographs showed the sizes of primary particles were in the range of 6-20 nm. The increase of vanadium doping promoted the particle growth, and enhanced "red-shift" in the UV-Vis absorption spectra. The XPS (X-ray photoelectron spectroscopy) could not detect vanadium indicating negligible vanadium on the surface of catalysts, furthermore, there were also no peak of vanadium oxide in the XRD patterns. XAS (X-ray absorption spectroscopy) analysis indicating $\mathrm{V}^{4+}$ instead of $\mathrm{V}^{5+}$ implied that vanadium either substituted $\mathrm{Ti}^{4+}$ site or embedded in the vacancy of $\mathrm{TiO}_{2}$ structure. Therefore, vanadium was concluded to be highly dispersed inside the $\mathrm{TiO}_{2}$ structure. The photocatalytic activity was evaluated by the degradation of crystal violet (CV) and methylene blue (MB) under visible light irradiation. The degradation rate of $\mathrm{CV}$ and $\mathrm{MB}$ on $\mathrm{V}$-doped $\mathrm{TiO}_{2}$ were higher than those of pure $\mathrm{TiO}_{2}$. As the results, V-doped $\mathrm{TiO}_{2}$ possessed better absorption ability of visible light.
\end{abstract}

(C) 2004 Elsevier B.V. All rights reserved.

Keywords: Titania; Vanadium doping; Visible-light photocatalyst; Sol-gel

\section{Introduction}

Titania is a well-known photocatalyst. Many applications using titania in photo reactions have been successfully developed, such as the purification of contaminated water and the remediation of polluted air [1]. However, most applications so far are limited to UV light irradiation because the light absorption edge of pure titania is less than $380 \mathrm{~nm}$. More than $96 \%$ solar light reaches earth surface is in the range of visible light (mostly 400-600 nm) since most UV is filtered by ozone layer. Therefore, a visible-light response photocatalyst becomes a recent trend in order to take full advantage of visible light. A few of visible-light photocatalysts were reported recently. Asahi et al. [2] reported a nitrogen doped titania possessed viable light photocatalytic activity in the photodegradation of methylene blue and acetaldehyde and its hydrophilicity. Anpo et al. [3] used ion implantation to dope a series of transition metal, such $\mathrm{V}, \mathrm{Cr}$ and $\mathrm{Ni}$ into $\mathrm{TiO}_{2}$ films with band gap shifting to visible light. Zhoa et al. [4] prepared a $\mathrm{V} / \mathrm{TiO}_{2}$ film and found an increase doping of vanadium resulting in further red-shift in UV-Vis spectroscopy. A series of transition metal were incorporated in

\footnotetext{
* Corresponding author. Tel.: +886-223631994; fax: +886-236323040. E-mail address: cswu@ntu.edu.tw (J.C.-S. Wu).
}

$\mathrm{TiO}_{2}$ and tested by photoreaction under visible light by Choi et al. [5]. Klosek and Raffrey [6] deposited $\mathrm{V}$ on a $\mathrm{TiO}_{2}$ film with dip coating technique, and obtained a monolayer vanadium, which was active using visible light (396-450 nm). In summary, vanadium doping provides a promising strategy to improve the photoactivity of titania under visible light.

The sol-gel process is one of the versatile methods to prepare nano-size materials. This technique does not require complicated instruments such as chemical vapor deposition. It provides a simple and easy means of synthesizing nano-size particles, which is essential for nano catalysts. The incorporation of an active metal in the sol during the gelation stage allows the metal to have a direct interaction with support, therefore the material posses special catalytic properties. One of the most promising photocatalysts for $\mathrm{CO}_{2}$ photoreduction was supported copper titania which was previously synthesized using sol-gel method in our lab [7]. Although titania catalysts have been extensively studied, the procedure of preparing photocatalytic metal-doped titania are still of great interesting.

The research is aimed to develop a visible-light response catalyst via vanadium doping. The objective is to prepare a uniformly and highly dispersed state of the $\mathrm{V}^{4+}$ incorporated titania photocatalyst so that its electronic properties is modified, enabling the absorption of visible light [8]. 


\section{Experimental}

\subsection{Preparation of catalysts}

Two methods were used to dope vanadium in $\mathrm{TiO}_{2}$ catalyst. Fig. 1 illustrates the first modified sol-gel procedure. Vanadyl acetylacetonate was completely dissolved in the $n$-butanol solution. Acetic acid was mixed in titanium butoxide. The molar ratio of titanium butoxide, acetic acid and $n$-butanol was 1:4:4. The atomic ratio of vanadium was calculated based on the desired V/Ti ratio and added in butanol. Then, the above two solution were mixed and hydrolyzed by the water generated via the esterification of acetic and butanol. The hydrolysis was completed after $24 \mathrm{~h}$, then the solution was dried at $150{ }^{\circ} \mathrm{C}$ and pulverized to powder. The dried gel was then calcined at $400{ }^{\circ} \mathrm{C}$ for $30 \mathrm{~min}$. The catalysts prepared by this procedure were assigned $\mathrm{V} / \mathrm{TiO}_{2}-\mathrm{NE}$.

The second method was carried in a cooled acidic aqueous solution shown in Fig. 2. Vanadium chloride was dissolved completely in ethanol, then mixed into titanium butoxide. The volume of ethanol was 10 times of ethanol/titanium butoxide solution. The amount of vanadium was calculated based on the desired V/Ti ratio. The mixed solution was slowly drop-by-drop added in a $0.1 \mathrm{M} \mathrm{HCl}$ solution, which volume was 10 times of ethanol/titanium butoxide solution, and quickly hydrolyzed due to large amount of water. During this process, the solution was kept cooled at near $0^{\circ} \mathrm{C}$ in a bath by circulating chilled water. The solution was dried at $110^{\circ} \mathrm{C}$, then following the same procedure of the first method. The catalysts prepared by this procedure were assigned $\mathrm{V} / \mathrm{TiO}_{2}-\mathrm{C}$.

\subsection{Characterization}

The specific surface area of the $\mathrm{V} / \mathrm{TiO}_{2}$ catalyst was measured by $\mathrm{N}_{2}$ adsorption using a Micrometrics ASAP 2010. A diffuse reflectance UV-Vis Spectrophotometer (HITACHI,

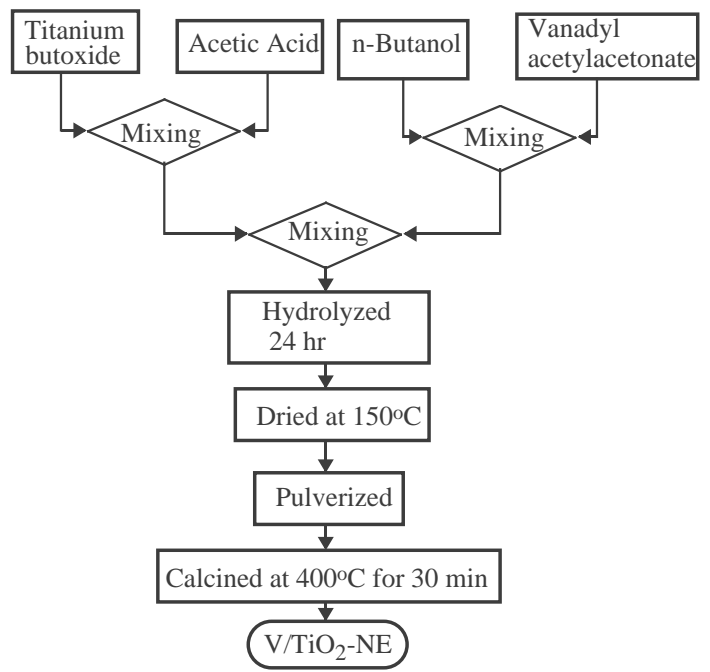

Fig. 1. Procedure of catalysts by non aqueous sol-gel, $\mathrm{V} / \mathrm{TiO}_{2}-\mathrm{NE}$.

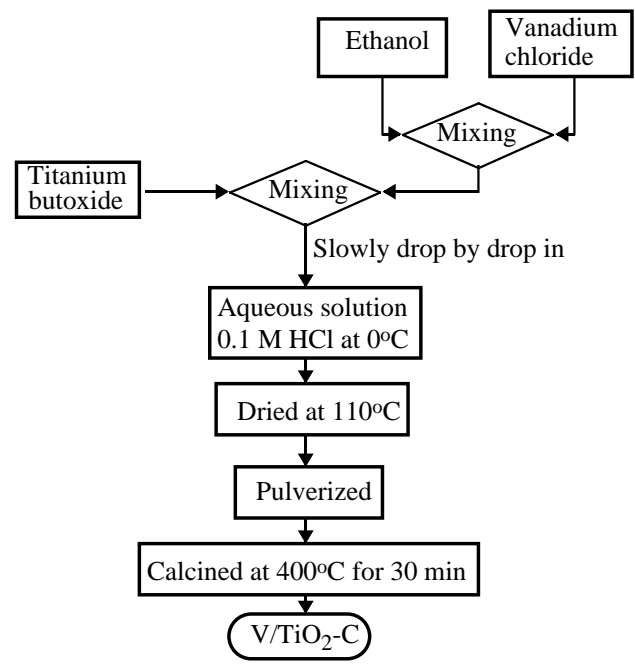

Fig. 2. Procedure of catalyst by cooled water hydrolysis, $\mathrm{V} / \mathrm{TiO}_{2}-\mathrm{C}$.

U3410) was employed to obtain the UV-Vis absorption spectra. The crystalline phase was identified by X-ray diffractometry (XRD) on a MAC (model M03XHF, Material Analysis and Characterization, Japan). X-ray photoelectron spectroscopy (XPS) was performed using VG Microtech MT500, operated with a constant pass energy of $50 \mathrm{eV}$ and with $\mathrm{Mg}$ $\mathrm{K} \alpha$ radiation as the excitation source $(h v=1253.6 \mathrm{eV})$. The catalyst was pressed into a pellet, and then adhered on a sample holder by carbon tape. Oxygen $\left(1 \mathrm{~s}, 530.7 \mathrm{eV}\right.$ for $\left.\mathrm{TiO}_{2}\right)$ and carbon $(1 \mathrm{~s}, 284.5 \mathrm{eV})$ were taken as internal standards for binding energy calibration. A transmission electron microscope (TEM), Hitachi H-7100, was applied to observe the morphology of catalysts and estimate the particle size.

The X-ray absorption spectra (XAS) of the V and Ti K-edge for the catalysts were measured at the Wiggler 17C station of the Taiwan Synchrotron Radiation Center in Hsinchu Science-based Industrial Park. Fluorescence mode was used to measure vanadium in titania catalysts. The powder sample was pressed in a sample holder positioned at $45^{\circ}$ to the incident $\mathrm{X}$-ray beam in a sample box. The fluorescent X-rays from the sample passed through a Ti-filter and reached the detector. The filter was used to avoid the interference from other atoms or incident X-rays. The measurement of titanium was in transition mode directly. The $\mathrm{X}$-ray photon energy varied across and beyond the absorption edge of the measured atom. For vanadium, it was in the range from $200 \mathrm{eV}$ below the vanadium absorption edge at 5465 to $800 \mathrm{eV}$ above it. The intensities of both fluorescent $\left(I_{\mathrm{f}}\right)$ and incident $\left(I_{\mathrm{o}}\right)$ X-rays were measured to calculate the absorption coefficient $(\mu)$ for the atoms of interest using the equation, $\mu x=I_{\mathrm{o}} / I_{\mathrm{f}}$, where $x$ is the thickness of the sample. Spectral analysis followed the standard steps of background correction and normalization before the near edge absorption structure was determined. Moreover, the spectra of pure $\mathrm{V}_{2} \mathrm{O}_{4}$ and $\mathrm{V}_{2} \mathrm{O}_{5}$ powder were measured as standard references. 


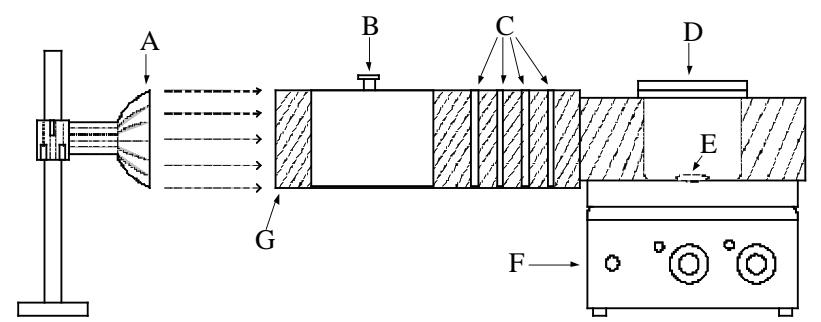

Fig. 3. Schematic of visible-light photo reaction system: (A) light; (B) IR filter (water); (C) UV filters; (D) Pyrex reactor; (E) magnetic rod; (F) stirrer; (G) light channel.

\subsection{Photo degradation of crystal violet and methylene blue}

The experiment of the $\mathrm{CV}$ or MB photo degradation was carried out in a visible-light Pyrex reactor. Fig. 3 depicts the visible-light photo reactor. The light source was a Philips CDM-R lamp with power $73 \mathrm{~W}$ and illumination $4850 \mathrm{~lm}$. The IR $(>700 \mathrm{~nm})$ and UV $(<400 \mathrm{~nm})$ lights were filtered by a water bottle and UV filters, respectively. A background of $\mathrm{MB}$ or $\mathrm{CV}$ degradation was carried under irradiation without catalyst first. The photocatalytic degradation rate was calculated by subtracting the background rate.

A weight $0.05 \mathrm{~g}$ of catalyst powder was suspended in either crystal violet $(\mathrm{CV})$ or methylene blue (MB) aqueous solution. The concentration of $\mathrm{CV}$ was $1.3 \times 10^{-5} \mathrm{M}$ prepared by dissolving $0.01 \mathrm{~g}$ in $350 \mathrm{ml}$ de-ionized water. The amount of $\mathrm{MB}, 0.0037 \mathrm{~g}$, was dissolved in $350 \mathrm{ml}$ de-ionized water forming a $2.8 \times 10^{-5} \mathrm{M}$ solution. The solution was stirred and reached adsorption equilibrium with catalyst before a lamp was turned on to start the photo reaction. An UV-Vis spectrometer (Shimadzu, UV-210A) monitored the concentration changes of $\mathrm{CV}$ and MB using wavelength 590.5 and $661.0 \mathrm{~nm}$, respectively. A linear calibration of absorption vs. concentration was obtained either $\mathrm{CV}$ or MB.

\section{Results and discussion}

\subsection{Characteristics of catalysts}

Table 1 summaries the specific surface area, mean pore size and pore volume of the catalysts and Degussa P25 titania. The $\mathrm{V} / \mathrm{TiO}_{2}-\mathrm{C}$ series gave specific surface area over $110 \mathrm{~m}^{2} / \mathrm{g}$, while those of $\mathrm{V} / \mathrm{TiO}_{2}-\mathrm{NE}$ ranged from 37 to $47 \mathrm{~m}^{2} / \mathrm{g}$. The pore sizes were in the meso pore region. Fig. 4(a) and (b) displays the TEM micrographs of $\mathrm{V} / \mathrm{TiO}_{2}-\mathrm{C}$ and $\mathrm{V} / \mathrm{TiO}_{2}-\mathrm{NE}$, respectively, The particle sizes of $\mathrm{V} / \mathrm{TiO}_{2}-\mathrm{C}$ ranged from 6 to $8 \mathrm{~nm}$, while those of $\mathrm{V} / \mathrm{TiO}_{2}-\mathrm{NE}$ were around $20 \mathrm{~nm}$.

Fig. 5(A) and (B) show the XRD patterns of $\mathrm{V} / \mathrm{TiO}_{2}-\mathrm{C}$ and $\mathrm{V} / \mathrm{TiO}_{2}-\mathrm{NE}$, respectively, indicating all anatase phases. All catalysts were stable in anatase using our preparation method, even after calcined temperature up to $700^{\circ} \mathrm{C}$. No characteristic peak of vanadium oxides $\left(\mathrm{V}_{2} \mathrm{O}_{5}\right.$ and $\left.\mathrm{V}_{2} \mathrm{O}_{4}\right)$

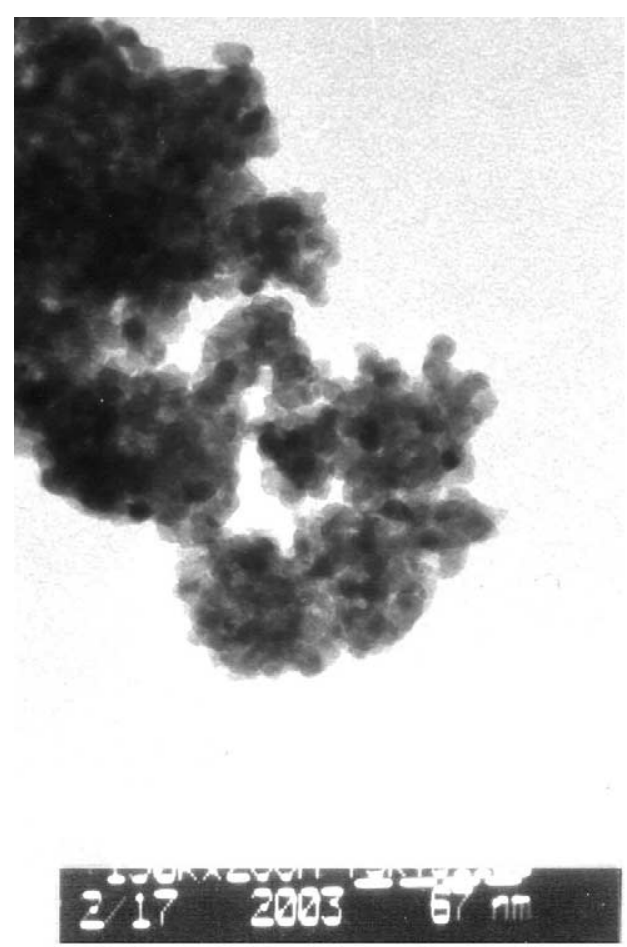

(a) $0.02 \mathrm{~V} / \mathrm{TiO} 2-\mathrm{C}$

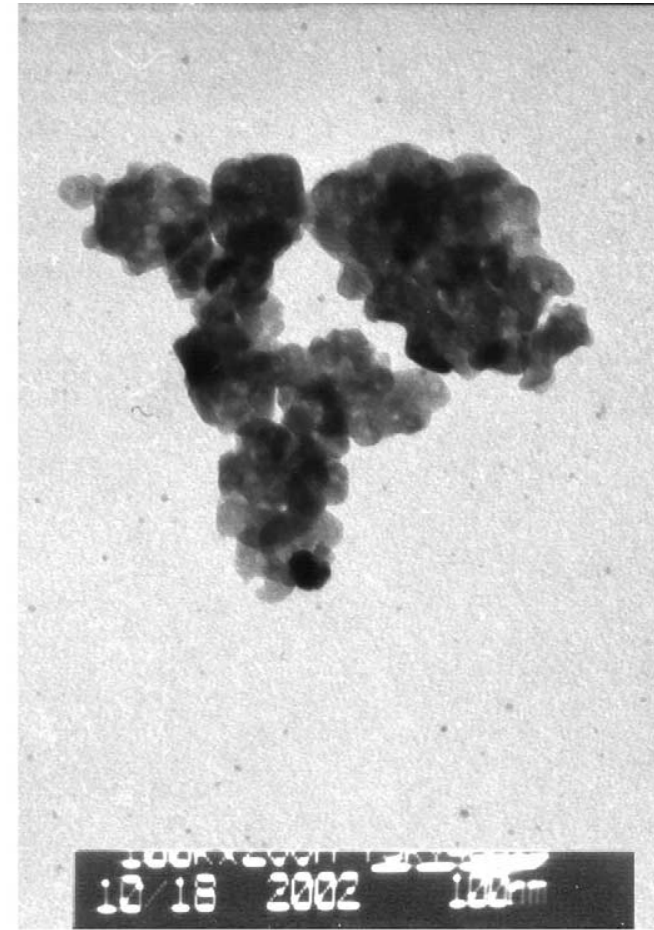

(b) $0.015 \mathrm{~V} / \mathrm{TiO} 2-\mathrm{NE}$

Fig. 4. Fig. 4(a) and (b) display the TEM micrographs: (a) $0.02-\mathrm{V} / \mathrm{TiO}_{2}-\mathrm{C}$; (b) $0.015-\mathrm{V} / \mathrm{TiO}_{2}-\mathrm{NE}$ catalysts. 
Table 1

Specific area, median pore size and pore volume of $\mathrm{V} / \mathrm{TiO}_{2}$ catalysts

\begin{tabular}{llcl}
\hline Catalyst & $\begin{array}{l}\text { Specific area } \\
\left(\mathrm{m}^{2} / \mathrm{g}\right)\end{array}$ & $\begin{array}{l}\text { Median pore } \\
(\mathrm{nm})\end{array}$ & $\begin{array}{l}\text { Pore volume } \\
\left(\mathrm{cm}^{3} / \mathrm{g}\right)\end{array}$ \\
\hline $0.01-\mathrm{V} / \mathrm{TiO}_{2}-\mathrm{C}$ & 112.6 & 4.4 & 0.16 \\
$0.02-\mathrm{V} / \mathrm{TiO}_{2}-\mathrm{C}$ & 116.8 & 4.4 & 0.17 \\
$0.029-\mathrm{V} / \mathrm{TiO}_{2}-\mathrm{C}$ & 117.5 & 4.4 & 0.16 \\
$0.035-\mathrm{V} / \mathrm{TiO}_{2}-\mathrm{C}$ & 128.6 & 4.5 & 0.16 \\
$0.052-\mathrm{V} / \mathrm{TiO}_{2}-\mathrm{C}$ & 127.6 & 4.6 & 0.16 \\
$0.025-\mathrm{V} / \mathrm{TiO}_{2}-\mathrm{NE}$ & 47.7 & 4.8 & 0.08 \\
$0.05-\mathrm{V} / \mathrm{TiO}_{2}-\mathrm{NE}$ & 41.6 & 6.4 & 0.09 \\
$0.08-\mathrm{V} / \mathrm{TiO}_{2}-\mathrm{NE}$ & 42.5 & 6.3 & 0.08 \\
$\mathrm{P} 25$ & 53.7 & 12.3 & 0.17
\end{tabular}

were found in the XRD patterns implying either vanadium was incorporated in the crystalline of $\mathrm{TiO}_{2}$, or vanadium oxide was very small and highly dispersed. The crystallite sizes estimated from peak broadening were consistent with the observation in TEM micrographs (Fig. 4). The crystallite size increased with increasing vanadium loading on both $\mathrm{V} / \mathrm{TiO}_{2}$ catalysts.

Fig. 6(A) and (B) show the UV-Vis absorption spectra of $\mathrm{V} / \mathrm{TiO}_{2}-\mathrm{C}$ and $\mathrm{V} / \mathrm{TiO}_{2}-\mathrm{NE}$, respectively. The spectrum of pure $\mathrm{TiO}_{2}$, which was prepared by our method, is shown in Fig. 6(B) and is similar to that of Degussa P25 in Fig. 6(A). Compared with the spectrum of pure titania, the red-shift was clearly observed in the series of $\mathrm{V} / \mathrm{TiO}_{2}-\mathrm{C}$ and $\mathrm{V} / \mathrm{TiO}_{2}-\mathrm{NE}$ catalysts. The higher the vanadium doping, the greater red-shift was. The UV-Vis spectrum of $\mathrm{V}_{2} \mathrm{O}_{5}$ also displays in Fig. 7(a) for comparison. The tailing of absorption curves reveal that $\mathrm{V} / \mathrm{TiO}_{2}$ absorb the photon energy in the range of $380-750 \mathrm{~nm}$, and is different from that of pure $\mathrm{V}_{2} \mathrm{O}_{5}$ (near $500 \mathrm{~nm}$ ). The band gaps of catalysts are in the range of $3.2 \sim 2.8 \mathrm{eV}$. The $3 \mathrm{~d}$ orbital of vanadium might change the band gap of titania so that $\mathrm{V} / \mathrm{TiO}_{2}$ catalysts enable to absorb visible light.

The chemical status of vanadium was evaluated by XPS as shown in Fig. 7. Both $\mathrm{V} / \mathrm{TiO}_{2}-\mathrm{C}$ and $\mathrm{V} / \mathrm{TiO}_{2}-\mathrm{NE}$ gave the similar spectra. The signal of characteristic peaks of vanadium was very weak. The magnitude was so small that was comparable with the oxygen satellite peak. The binding energy of vanadium was near $517.3 \mathrm{eV}$ indicating $\mathrm{V}^{5+}$ species [9]. However, a shoulder of the peak at $516.1 \mathrm{eV}$ suggested $\mathrm{V}^{4+}$ species, too. XPS can only measure the elements on the most outer surface. Only very few vanadium was on the surface of the $\mathrm{TiO}_{2}$ particles indicating most vanadium located inside $\mathrm{TiO}_{2}$.

Fig. 8(A) and (B) show the X-ray adsorption near edge structure (XANES) of vanadium in $\mathrm{V} / \mathrm{TiO}_{2}-\mathrm{C}$ and $\mathrm{V} / \mathrm{TiO}_{2}-\mathrm{NE}$, respectively. The XANES of titanium in $\mathrm{V} / \mathrm{TiO}_{2}$ was found the same as that in pure anatase $\mathrm{TiO}_{2}$, but significantly different from that in pure rutile $\mathrm{TiO}_{2}$. Such result of anatase phase was consistent with the XRD pattern. The XANES of pure $\mathrm{V}_{2} \mathrm{O}_{4}$ and $\mathrm{V}_{2} \mathrm{O}_{5}$ were also measured and depicted in Fig. 8 for the comparison of either $\mathrm{V}^{4+}$ or $\mathrm{V}^{5+}$. An absorption pre-edge at $5470 \mathrm{eV}$ was observed in
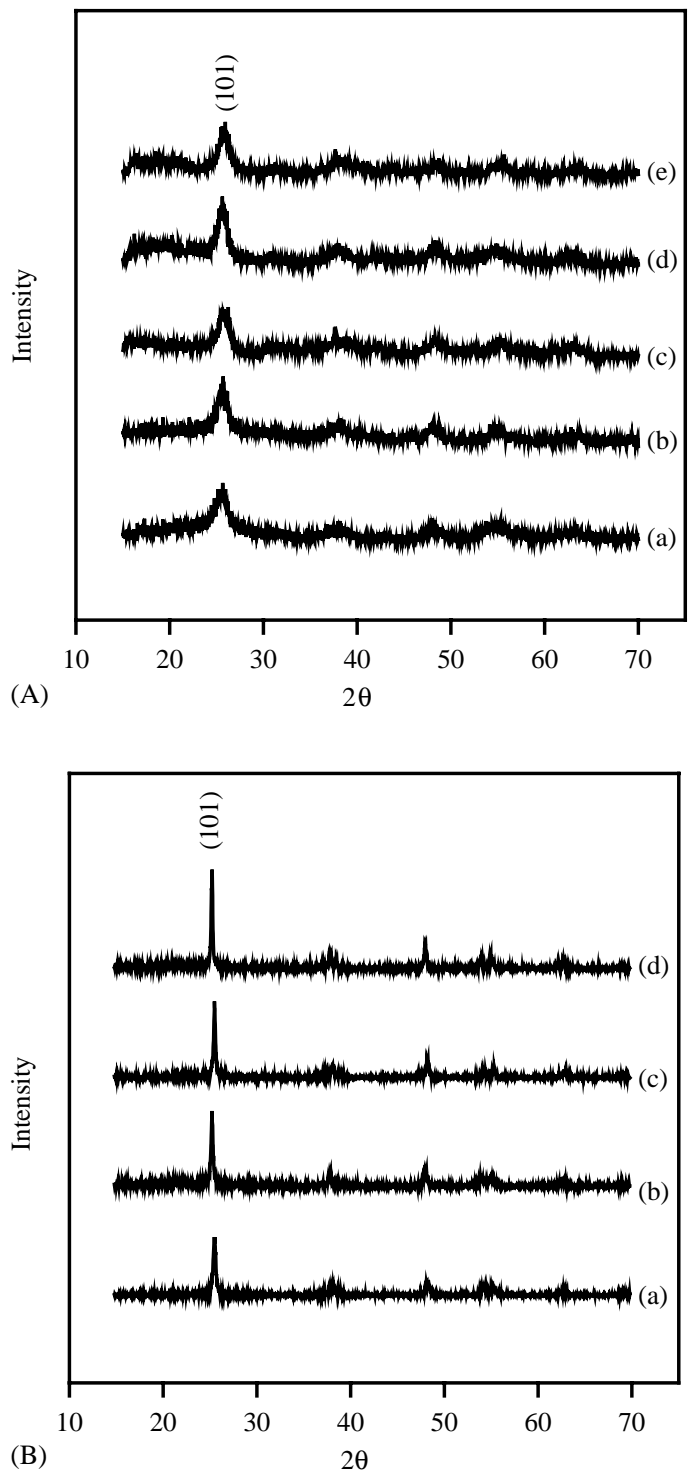

Fig. 5. (A) XRD patterns of $\mathrm{V} / \mathrm{TiO}_{2}-\mathrm{C}$ catalysts calcined $400{ }^{\circ} \mathrm{C}$ : (a) $\mathrm{V} / \mathrm{Ti}=0.01$, (b) $\mathrm{V} / \mathrm{Ti}=0.02$, (c) $\mathrm{V} / \mathrm{Ti}=0.029$, (d) $\mathrm{V} / \mathrm{Ti}=0.035$, (e) $\mathrm{V} / \mathrm{Ti}=0.052$; (B) XRD patterns of $\mathrm{V} / \mathrm{TiO}_{2}-\mathrm{NE}$ catalysts calcined at $400^{\circ} \mathrm{C}$ : (a) $\mathrm{V} / \mathrm{Ti}=0.015$, (b) $\mathrm{V} / \mathrm{Ti}=0.025$, (c) $\mathrm{V} / \mathrm{Ti}=0.05$, (d) $\mathrm{V} / \mathrm{Ti}=0.08$

either $\mathrm{V}_{2} \mathrm{O}_{4}$ or $\mathrm{V}_{2} \mathrm{O}_{5}$. The shape of absorption pre-edge from $\mathrm{V} / \mathrm{TiO}_{2}-\mathrm{C}$ and $\mathrm{V} / \mathrm{TiO}_{2}-\mathrm{NE}$ is symmetric and closed to that of $\mathrm{V}_{2} \mathrm{O}_{5}$. Three post-edge absorption peaks, 5486, 5494 and $5506 \mathrm{eV}$ can be found in $\mathrm{V}_{2} \mathrm{O}_{5}$. The post-edge absorption peaks of $\mathrm{V}_{2} \mathrm{O}_{4}$ are located near 5482, 5489 and $5502 \mathrm{eV}$, although they are not sharp. The XANES's of $\mathrm{V} / \mathrm{TiO}_{2}-\mathrm{C}$ and $\mathrm{V} / \mathrm{TiO}_{2}-\mathrm{NE}$ are all similar, and show two post-edge absorption peaks at 5488 and $5501 \mathrm{eV}$. Those two peaks may be composed of those peaks of $\mathrm{V}_{2} \mathrm{O}_{5}$ and $\mathrm{V}_{2} \mathrm{O}_{4}$. Therefore, the chemical status of vanadium in $\mathrm{V} / \mathrm{TiO}_{2}-\mathrm{C}$ and $\mathrm{V} / \mathrm{TiO}_{2}-\mathrm{NE}$ co-existed both $\mathrm{V}^{4+}$ and $\mathrm{V}^{5+}$. The chemical status is an important evidence to deduce whether vanadium is located in the $\mathrm{TiO}_{2}$ octahedral lattice. $\mathrm{The} \mathrm{V}^{4+}$ 

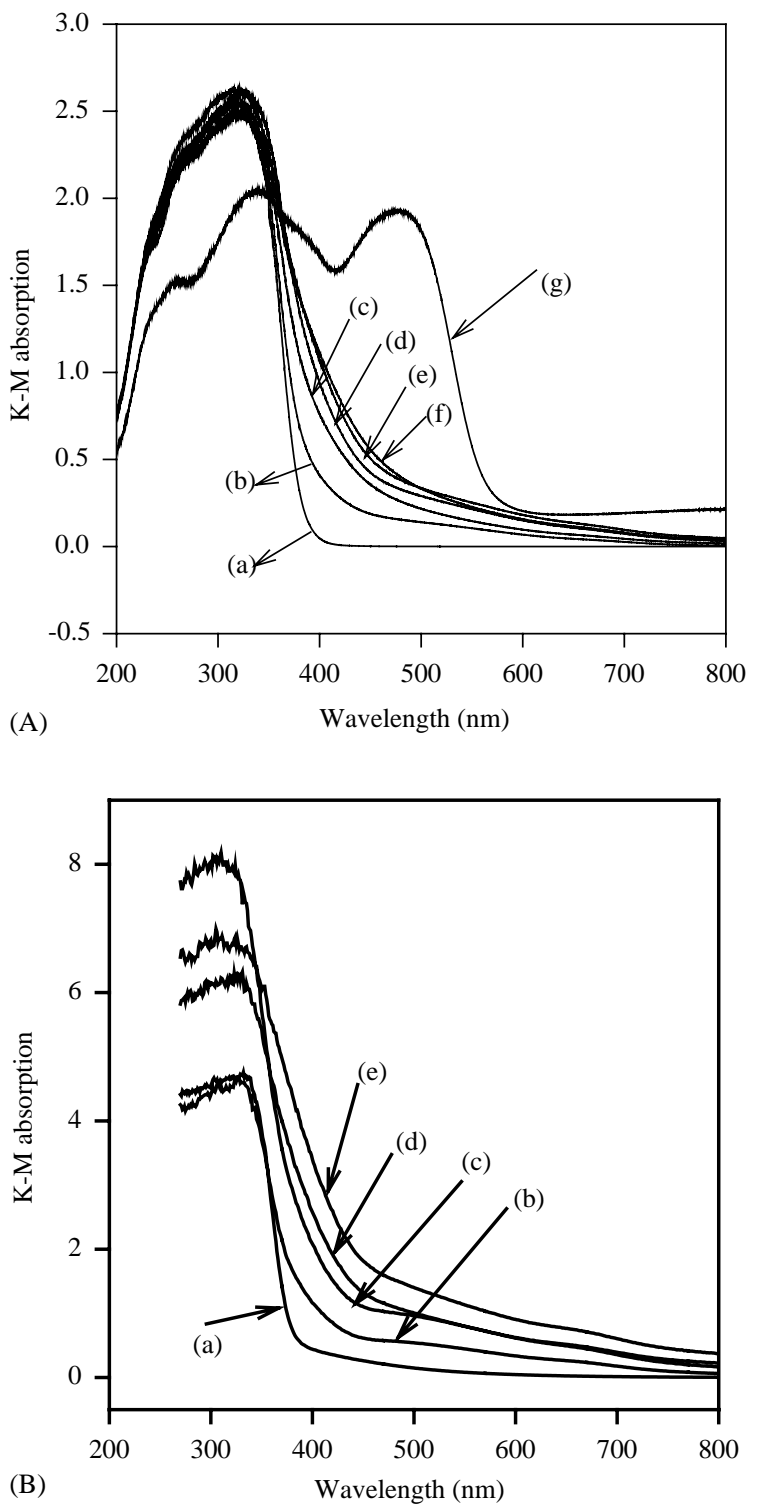

Fig. 6. (A) UV-Vis absorption spectra of $\mathrm{V} / \mathrm{TiO}_{2}-\mathrm{C}$ : (a) $\mathrm{P} 25$, (b) $\mathrm{V} / \mathrm{Ti}=0.01$, (c) $\mathrm{V} / \mathrm{Ti}=0.02$, (d) $\mathrm{V} / \mathrm{Ti}=0.029$, (e) $\mathrm{V} / \mathrm{Ti}=0.035$, (f) $\mathrm{V} / \mathrm{Ti}=0.052$, (g) $\mathrm{V}_{2} \mathrm{O}_{5}$; (B) UV-Vis absorption spectra of $\mathrm{V} / \mathrm{TiO}_{2}-\mathrm{NE}$ : (a) $\mathrm{TiO}_{2}-\mathrm{NE}$, (b) $\mathrm{V} / \mathrm{Ti}=0.015$, (c) $\mathrm{V} / \mathrm{Ti}=0.025$, (d) $\mathrm{V} / \mathrm{Ti}=0.05$, (e) $\mathrm{V} / \mathrm{Ti}=0.08$.

is possible in the octahedral lattice of $\mathrm{TiO}_{2}$, while $\mathrm{V}^{5+}$ may be $\mathrm{V}_{2} \mathrm{O}_{5}$ highly dispersed within crystalline of $\mathrm{TiO}_{2}$.

\subsection{Photocatalytic activity}

The photocatalytic activity of $\mathrm{V} / \mathrm{TiO}_{2}$ catalyst was tested by the de-colorization of $\mathrm{CV}$ and $\mathrm{MB}$ solutions. A CV molecule can be degraded into aryl compounds representing the photo oxidation activity [10]. A cationic form of MB can be reduced and changed blue to colorless by accepting an electron representing the photo reduction activity [11]. Table 2 lists the photo degradation rates of $\mathrm{V} / \mathrm{TiO}_{2}-\mathrm{C}$ and

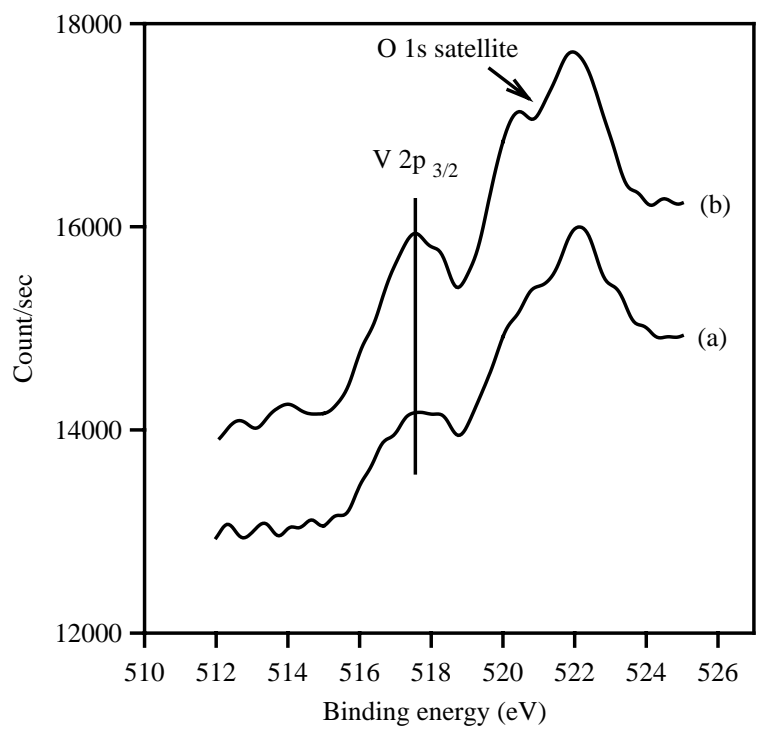

Fig. 7. XPS of vanadium $2 \mathrm{p}_{3 / 2}$ spectra of $\mathrm{V} / \mathrm{TiO}_{2}-\mathrm{C}$ : (a) $\mathrm{V} / \mathrm{Ti}=0.035$, (b) $\mathrm{V} / \mathrm{Ti}=0.052$.

$\mathrm{V} / \mathrm{TiO}_{2}-\mathrm{NE}$ irradiated under visible light at ambient temperature. The rate was calculated based on a 6-h irradiation, and was found zeroth order at the experimental conditions. The catalyst, $0.035 \mathrm{~V} / \mathrm{TiO}_{2}-\mathrm{C}$, showed the highest rates $3.07 \times 10^{-7}$ and $3.87 \times 10^{-7} \mathrm{~mol} / \mathrm{l} \mathrm{h}$ of $\mathrm{CV}$ and $\mathrm{MB}$, respectively. The maximum photo reaction rates of $\mathrm{CV}$ and MB were $3.61 \times 10^{-7}$ and $3.71 \times 10^{-7} \mathrm{~mol} / \mathrm{l} \mathrm{h}$, respectively, on $0.05 \mathrm{~V} / \mathrm{TiO}_{2}-\mathrm{NE}$. The pure $\mathrm{TiO}_{2}$ was expected to be no photo activity but showed perceivable photo reaction rates because of a little portion of residue UV entering photo reactor. Table 3 lists the photon intensity of original light source and after IR and UV filters indicating a small port of UV-A and UV-C can enter the photo reactor. After UV portion was filtered, the photon intensity of UV-A and UV-C were reduced to only 1.0 and $10.6 \mu \mathrm{W} / \mathrm{cm}^{2}$, respectively, compared with near $40,000 \mu \mathrm{W} / \mathrm{cm}^{2}$ of visible light.

Table 2

Photo degradation rates of crystal violet (CV) and methyl blue (MB) with initial concentration, $1.3 \times 10^{-5}$ and $2.8 \times 10^{-5} \mathrm{M}$, respectively, under visible-light irradiation

\begin{tabular}{lll}
\hline Catalyst & $\begin{array}{l}\mathrm{CV} \text { rate } \\
\left(10^{-7} \mathrm{~mol} / \mathrm{l} \mathrm{h}\right)\end{array}$ & $\begin{array}{l}\mathrm{MB} \text { rate } \\
\left(10^{-7} \mathrm{~mol} / \mathrm{l} \mathrm{h}\right)\end{array}$ \\
\hline $\mathrm{TiO}_{2}-\mathrm{C}$ & 1.73 & 2.02 \\
$0.01-\mathrm{V} / \mathrm{TiO}_{2}-\mathrm{C}$ & 0.67 & 2.70 \\
$0.02-\mathrm{V} / \mathrm{TiO}_{2}-\mathrm{C}$ & 1.30 & 3.90 \\
$0.029-\mathrm{V} / \mathrm{TiO}_{2}-\mathrm{C}$ & 2.55 & 3.12 \\
$0.035-\mathrm{V} / \mathrm{TiO}_{2}-\mathrm{C}$ & 3.07 & 3.87 \\
$0.052-\mathrm{V} / \mathrm{TiO}_{2}-\mathrm{C}$ & 2.21 & 3.62 \\
$\mathrm{TiO} 2-\mathrm{NE}_{0.015-\mathrm{TiO}_{2}-\mathrm{NE}}$ & 2.44 & 3.01 \\
$0.025-\mathrm{TiO}_{2}-\mathrm{NE}$ & 2.44 & 3.17 \\
$0.05-\mathrm{TiO}_{2}-\mathrm{NE}$ & 2.12 & 3.67 \\
$0.08-\mathrm{TiO}_{2}-\mathrm{NE}$ & 3.61 & 3.71 \\
\hline
\end{tabular}



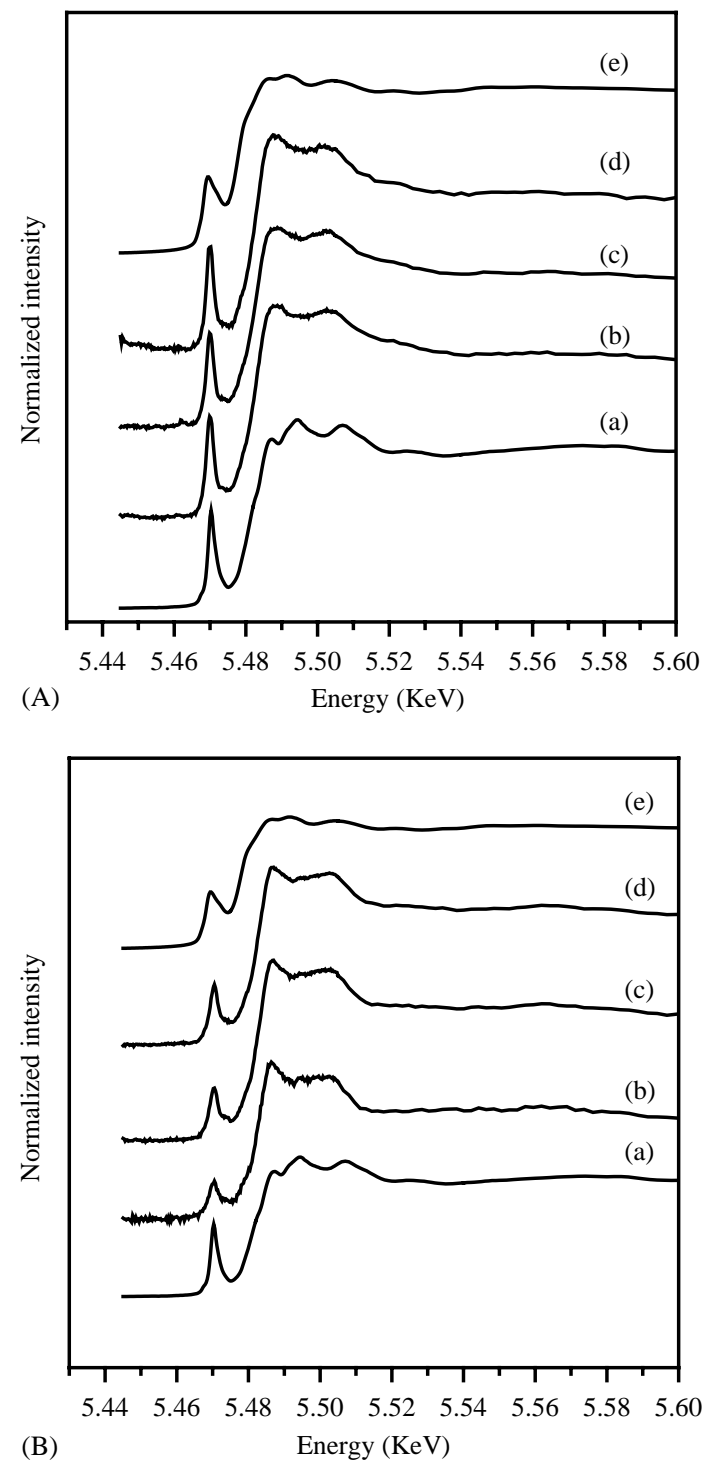

Fig. 8. (A) Vanadium XANES of $\mathrm{V} / \mathrm{TiO}_{2}-\mathrm{C}$ : (a) $\mathrm{V}_{2} \mathrm{O}_{5}$, (b) $\mathrm{V} / \mathrm{Ti}=0.029$, (c) $\mathrm{V} / \mathrm{Ti}=0.035$, (d) $\mathrm{V} / \mathrm{Ti}=0.052$, (e) $\mathrm{V}_{2} \mathrm{O}_{4}$; (B) vanadium XANES of $\mathrm{V} / \mathrm{TiO}_{2}-\mathrm{NE}$, (a) $\mathrm{V}_{2} \mathrm{O}_{5}$, (b) $\mathrm{V} / \mathrm{Ti}=0.025$, (c) $\mathrm{V} / \mathrm{Ti}=0.05$, (d) $\mathrm{V} / \mathrm{Ti}=0.08$, (e) $\mathrm{V}_{2} \mathrm{O}_{4}$.

A photo reaction is initiated by the electron and hole via the excitation of photons. The transformation of photons to electron/hole pair, i.e., quantum efficiency, is one of crucial factors in a photo reaction. The quantum efficiency of UV light is much higher than that of visible light because of its

Table 3

The filtering results of UV light

\begin{tabular}{lll}
\hline & UV-A $\left(\mu \mathrm{W} / \mathrm{cm}^{2}\right)^{\mathrm{a}}$ & $\mathrm{UV}-\mathrm{C}\left(\mu \mathrm{W} / \mathrm{cm}^{2}\right)^{\mathrm{a}}$ \\
& $365 \mathrm{~nm}$ & $254 \mathrm{~nm}$ \\
\hline Original light & 1023.5 & 18.1 \\
IR and UV filtered & 1.0 & 10.6 \\
\hline
\end{tabular}

\footnotetext{
${ }^{a}$ Measured by a Lumen meter with specific wavelength at 365 or $254 \mathrm{~nm}$.
}

high photon energy. Therefore, even a small amount of UV can activate photo reaction effectively than that of visible light. In addition, both $\mathrm{TiO}_{2}$ and $\mathrm{V} / \mathrm{TiO}_{2}$ catalyst have higher UV absorption efficiency than visible light. The absorption of visible light on $\mathrm{V} / \mathrm{TiO}{ }_{2}$ is higher than that on pure $\mathrm{TiO}_{2}$ as shown in Fig. 6. However, the enhancement of photo activity by visible-light is still surpassed by small amount of UV. not so drastically. That's why only marginally increasing photo activity were observed in $\mathrm{V} / \mathrm{TiO}_{2}$ catalysts under visible-light irradiation.

\section{Conclusion}

The modified sol-gel methods offer successful routes to synthesize V-doped titania catalysts. Vanadium ion in $\mathrm{TiO}_{2}$ may change the band gap between conduction and valence bands. Thus, V-doped titania acquires the capability of absorbing visible light and shows a 'red-shift' in the UV-Vis spectra. The results of photocatalytic reaction indicate that the V-doped $\mathrm{TiO}_{2}$ has higher activity than pure $\mathrm{TiO}_{2}$ under visible light irradiation. The improvement is due to the highly dispersed vanadium in the $\mathrm{TiO}_{2}$ crystallite.

\section{Acknowledgements}

The authors would like to thank the National Science Council of Taiwan, the Republic of China, for financially supporting this research under contract no. NSC-91-2214-E-002-021. Authors also thank Dr. Jyh-Fu Lee of the Wiggler 17C station of the Taiwan Synchrotron Radiation Center, and Ms. Chaoling Lai of the Surface Analysis Lab at the National Taiwan University for their effort in instrumental analysis.

\section{References}

[1] A. Fujishima, T.N. Rao, D.A. Tryk, Titanium dioxide photocatalysis, J. Photochem. Photobiol. C: Photochem. Rev. 1 (2000) 1-21.

[2] R. Asahi, T. Morikawa, T. Ohwaki, K. Aoki, Y. Taga, Visible-light photocatalysis in nitrogen-doped titanium oxides, Science 293 (2001) 269-271.

[3] M. Anpo, Y. Ichihashi, M. Takeuchi, H. Yamashita, Design of unique titanium oxide photocatalysts by an advanced metal ion-implantation method and photocatalytic reactions under visible light irradiation, Res. Chem. Intermediates 24 (42) (1998) 143-149.

[4] G. Zhao, H. Kozuka, H. Lin, T. Yoko, Sol-gel preparation of $\mathrm{Ti}_{1-x}-\mathrm{V}_{x} \mathrm{O}_{2}$ solid solution film electrodes with conspicuous photoresponse in the visible region, Thin Solid Films 339 (1999) 123-128.

[5] W. Choi, A. Termin, M. Hoffmann, The role of metal ion dopants in quantum-size $\mathrm{TiO}_{2}$ : correlation between photoactivity and charge carrier recombination dynamics, J. Phys. Chem. 98 (1994) 13669 13679.

[6] S. Klosek, D. Raffery, Visible light driven V-doped $\mathrm{TiO}_{2}$ photocatalyst and its photooxidation of ethanol, J. Phys. Chem. B 105 (2001) 2815-2819.

[7] I.-H. Tseng, W.-C. Chang, J.C.-S. Wu, Photoreduction of $\mathrm{CO}_{2}$ using sol-gel-derived titania and titania-supported copper catalysts, Appl. Catal. B: Environ. 37 (1) (2002) 37-48. 
[8] M. Anpo, H. Yamashita, S. Kanai, K. Sato, T. Fujimoto, Photocatalyst, process for producing the photocatalyst, and photocatalytical reaction method, US Patent 6,077,492 (2000).

[9] J.F. Moulder, W.F. Stickle, P.E. Sobol, K.D. Bomben, Handbook of $\mathrm{X}$-ray photoelectron spectroscopy, Physical Electronics, Inc., Eden Prairie, MN, USA, 1995.
[10] M. Saquib, M. Muneer, $\mathrm{TiO}_{2}$ mediated photocatalytic degradation of a triphenylmethane dye (gentian violet) in aqueous suspensions, Dyes Pigments 56 (2003) 37-49.

[11] A.G. Cook, R.M. Tollover, J.E. Williams, The blue bottle experiment revisited, J. Chem. Educ. 71 (2) (1994) 160-161. 